\title{
The role of nanogold in human tropical diseases: research, detection and therapy
}

\author{
Miguel Peixoto de Almeida • Sónia A. C. Carabineiro
}

Published online: 6 April 2013

(C) The Author(s) 2013. This article is published with open access at Springerlink.com

\section{Introduction}

The Special Programme for Research and Training in Tropical Diseases, based at and executed by the World Health Organization (WHO), states that these maladies affect millions of people across the world [1-5]. They are more common in tropical and subtropical regions, as in temperate climates the cold season is able to control the insects population, which are the most common disease carriers or vectors. The flies and mosquitos may carry parasites, bacteria or viruses that can infect humans and animals through a "bite", which transmits the illness agent through a subcutaneous blood exchange. Some factors like deforestation, exploration of tropical areas, and increasing international air travel to tropical regions lead to an increase of tropical diseases. For some of them, unfortunately, vaccines are still not available.

The recent explosive growth of nanogold applications in many areas [6-9], also comprises contributions to the health field [10-14]. In particular, gold can have a direct role in treatment and detection of tropical diseases, as shown by some studies found in literature. Besides some examples of molecular gold used directly against parasites and in research dealing with animal parasitic diseases [15-17], gold nanoparticles and gold complexes can also play a significant role that goes beyond the classical approach of confirmation diagnosis,

\footnotetext{
M. P. de Almeida • S. A. C. Carabineiro $(\square)$

Laboratory of Catalysis and Materials (LCM),

Associate Laboratory LSRE/LCM, Faculdade de Engenharia,

Universidade do Porto, Rua Dr. Roberto Frias,

4200-465 Porto, Portugal

e-mail: scarabin@fe.up.pt
}

based on detection of parasites in either blood or lymph by microscopy, as it will be explained below.

\section{Trypanosomiases}

About the diseases

There are two different types of human trypanosomiases [1,2]: the human African trypanosomiasis and the American trypanosomiasis. The latter is more studied, but it is important to also refer the progresses made so far on the former.

The human African trypanosomiasis, also known as "sleeping sickness", is a well-known tropical disease, caused by the protozoan parasites Trypanosoma brucei rhodesiense or Trypanosoma brucei gambiense. It is spread by a bite of an infected tsetse fly, which erupts into a red sore. Within a few weeks, it causes fever, swollen lymph glands, aching muscles and joints, headaches and irritability. In advanced stages, the disease attacks the central nervous system, causing changes in personality, alteration of the circadian rhythm, confusion, slurred speech, seizures, and difficulty walking or talking. These problems can develop over many years in the gambiense form and some months in the rhodesiense form. If not treated, it can cause death. An early diagnosis is of extreme importance for a better control of this sickness.

The American trypanosomiasis, or Chagas disease, is caused by the protozoan parasite Trypanosoma cruzi, generically schematized in Fig. 1. It is found mainly in Latin America, where it is mostly transmitted to humans by the faeces of triatomine bugs [2]. This disease can cause death from myocarditis or meningoencephallitis during its acute phase, in less than 5$10 \%$ of symptomatic cases. The evolution for the chronic phase (10-30 years after infection) can result in cardiac, digestive 


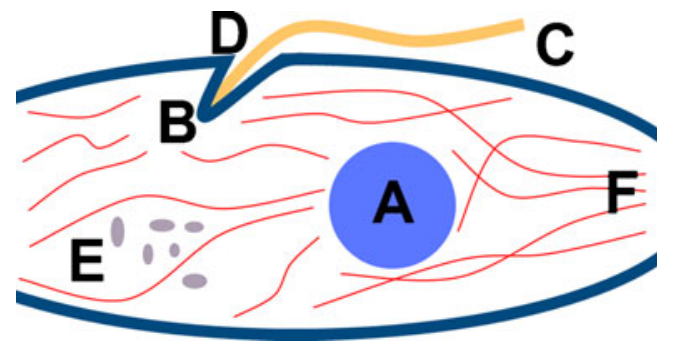

Fig. 1 Trypanosoma cruzi cell schematic representation (adapted from $[87,88])$. a Nucleus, b flagellar pocket, $\mathbf{c}$ flagellum, $\mathbf{d}$ cytostome, $\mathbf{e}$ cytoplasmic vesicles, $\mathbf{f}$ cytoskeleton

(megaesophagus and megacolon), or cardiodigestive problems in $30-40 \%$ of the infected patients [18].

Microscopy assays using nanogold

In 1997, Magez et al. [19], knowing that the protozoan Trypanosoma brucei is lysed by the cytokine tumor necrosis factor- $\alpha$ (TNF- $\alpha)$, prepared TNF- $\alpha$ gold nanoparticles (TNF- $\alpha$-AuNP) using commercial $10 \mathrm{~nm}$ gold beads. These TNF- $\alpha$-AuNP were endocytosed via coated pits and vesicles and are directed towards lysosome-like digestive organelles. The localization of TNF- $\alpha$ binding sites on intact parasites and a better understanding of intracellular uptake of TNF- $\alpha$ were possible precisely with the help of the conjugated colloidal gold particles. The bulk of the TNF- $\alpha$ gold labeling was localized in the flagellar pocket, where beads concentrated in coated pits. Sporadically, TNF- $\alpha-$ AuNP were found in association with the flagellum in the flagellar adhesion zone, at the entrance of the flagellar pocket, or in association with tiny filamentous material at more distant regions of the flagellum.

Soeiro et al. [20] performed ultrastructural analysis of the endocytic process (cellular uptake) using horseradish peroxidase (HRP) enzyme coupled to colloidal gold particles (HRPAuNP). The "in vitro" findings suggest that cardiomyocytes (cells of cardiac muscle) mannose receptors, localized at the sarcolemma (muscle cell membrane), mediate $T$. cruzi recognition and can be down-modulated by parasite infection.

Okuda and co-workers [21] used ultrathin sections of T. cruzi epimastigote forms. These assays, which reveal gold particles at the opening of flagellar pocket, concentrated in the cytostome region, were possible through immunogold labeling (a staining technique used in electron microscopy, where colloidal gold nanoparticles are usually attached to secondary antibodies, which are attached to primary antibodies designed to bind a specific protein or other cell component). The protocol consists in cytoskeletons incubation in the first antibody, which recognizes the cytoskeletons elements; then incubated in the second antibody, which recognizes the first antibody and have attached a $15 \mathrm{~nm}$ gold particle. Using electron microscopy to visualize the gold nanoparticles
(AuNP), and consequently the known proximity of the elements recognized by the antibody-antibody-AuNP configuration, the relationship between the cytostome, an endocytic organelle, and the flagellum was described for the first lime. Gold has high electron density which increases electron scatter enabling high contrast images.

A similar protocol allowed Monteiro et al. [22], in 2001, to describe the localization of chagasin, an endogenous tight-binding cysteine protease inhibitor in T. cruzi. Goldlabeled antibodies localized chagasin to the flagellar pocket and cytoplasmic vesicles of trypomastigotes and to the cell surface of amastigotes (the former are found in human blood and the later in tissues). Thin sections were incubated with affinity purified rabbit anti-chagasin followed by goldconjugated goat anti-rabbit Immunoglobulin G ( $\operatorname{IgG})$.

Silva et al. [23] evaluated the presence and distribution of the Ssp4 antigen in the different amastigote T. Cruzi populations using gold-labeled antibodies, allowing the observation with transmission electron microscopy. Goat antimouse IgG was labeled with $10 \mathrm{~nm}$ gold particles. These were mainly located inside cytoplasmic vesicles and the flagellar pocket, suggesting that Ssp4 is released by exocytosis into the flagellar pocket.

Recently, Acosta et al. [24] used immunogold electron microscopy analysis for providing a new insight to better understand the molecular pathogenesis of Chagas heart disease. They showed that there is a common epitope between cruzipain (a lysosomal major antigen from $T$. cruzi) and either myosin or other cardiac $O$-linked $N$-acetylglucosamine containing proteins.

Eger and Soares [25] described the visualization by confocal microscopy of ingested gold $(15 \mathrm{~nm})$ labeled transferrin in epimastigote forms of the protozoan T. cruzi. This is a promising imaging tool to explore the endocytic pathway in trypanosomes (and eventually adapted for other protozoans).

Detection methods using gold

In 2003, Diniz et al. [26], prepared a gold electrode for adsorbing a polypeptide chain formed by recombinant antigens: cytoplasmic repetitive antigen (CRA) and flagellar repetitive antigen (FRA) of T. cruzi. The goal was to develop a biosensor for Chagas disease, based on impedance spectroscopy, with the behavior of CRA/FRA antigens adsorbed on gold and platinum electrodes being investigated. The team also used platinum electrodes, which yielded similar results as those presented by gold; however, the marked influence of oxygen dissolved in solution on the electrochemical response of platinum, requires extensive deoxygenation of solutions prior each experiment. Consequently, gold electrodes have advantages. Under proper conditions, it is possible to distinguish between serum positive and negative to Chagas disease. 
Joining the last two methods (as an "immunotechnique" is applied, but gold acts as a supporting electrode for sensing purposes, instead of labeling), Ferreira et al. [27] immobilized Chagas disease antigens in a gold surface, and the anti- $T$. cruzi antibodies present in the serum sample were captured by the antigen, remaining connected to the solid phase. The human anti-IgG antibody conjugated to peroxidase (HRP) then reacted with immunocaptured anti-T. cruzi antibodies, if any present. The detection and quantification was ensured by peroxidase activity in presence of $\mathrm{H}_{2} \mathrm{O}_{2}$ and, in the presence of the iodide, this ion reacted with the reduced peroxidase. Under these conditions, the current intensity of $\mathrm{I}_{2}$ reduction was proportional to the amount of anti- $T$. cruzi antibodies in the serum real sample. This assembling is schematized in Fig. 2.

In a very similar approach, Ribone and co-workers [28] prepared bioelectrodes to detect IgG antibodies occurring in sera of patients suffering from American trypanosomiasis. The main difference from the previous description [27], is the use of two different thiols, 3-mercapto-1-propionic acid (MPA), 3-mercapto-1-propanesulfonic acid (MPSA), which provide sulfonate or carboxylic residues, for the electrostatic binding of the antigen. Figure 2 also applies to the assembling described in this work, where the linkage to the gold electrode is described generically as "thiol".

Foguel et al. [29] used the same principle for the construction of an amperometric imunosensor. The novelty here was the gold based electrode being obtained from a recordable compact disc (CD-R), then modified with 4-(methylmercapto)benzaldehyde for the immobilization of Tc85 protein of the T. cruzi. To access the metal layer of the CD-R, concentrated $\mathrm{HNO}_{3}$ was added on the surface and after 5-10 $\mathrm{min}$ the protective layers were totally removed. It is well known that organic monolayers with thiol or disulfide groups on the electrode surface are of great

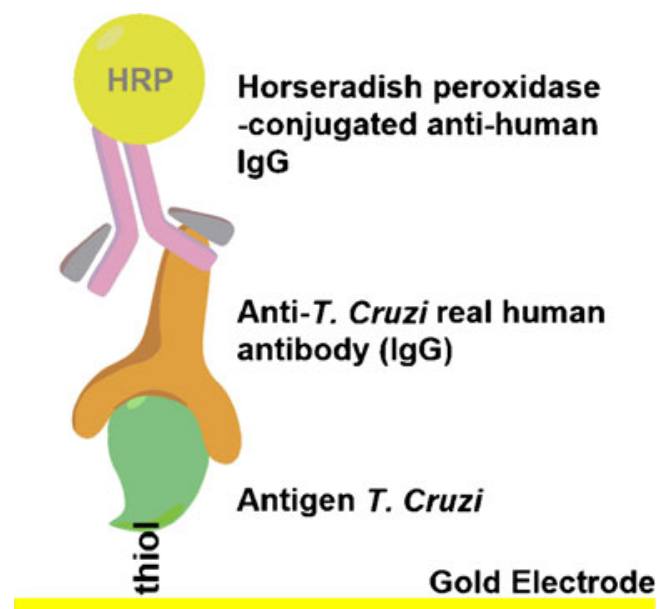

Fig. 2 Immunosensors supported on a gold electrode (adapted from $[29,30])$ interest due to the sulfur binding strongly to the gold surface. A molecule that presents this property is 4-(methylmercapto)benzaldehyde (SBZA), which has a mercapto group and maintains a free aldehydic group. In order to link the CD-R fragment and allow the amperometric process, a laminated copper wire was fixed and insulated with polytetrafluoroethylene (PTFE), so that the wire does not come into contact with the electrolyte solution, thus avoiding the oxidation and reduction of this copper.

Using a similar methodology, a microfluidic system coupled to a screen-printed carbon electrode (SPCE) was developed by Pereira and co-workers [30] for the quantitative determination of $\mathrm{IgG}$ specific antibodies present in serum samples of patients with Chagas disease. This time, HRP in the presence of $\mathrm{H}_{2} \mathrm{O}_{2}$ catalysed the oxidation of 4-tert-butylcatechol (4-TBC) and its back electrochemical reduction was detected on a modified electrode. The authors claimed that, compared with traditional IgG detection techniques, the immunosensor based on microfluidic technology showed a decrease in sample and reagent consumption, faster response times for analysis, and good reproducibility and did not require highly skilled technicians or expensive and dedicated equipment.

Deborggraeve et al. [31] developed a simple and rapid test for detection of amplified T. brucei DNA, the human African trypanosomiasis-polymerase chain reactionoligochromatography (HAT-PCR-OC). In this case, gold was used essentially as a colorimetric indicator. PCR products were visualized on a dipstick through hybridization with a gold-conjugated probe (oligochromatography), occurring in $5 \mathrm{~min}$. The lower detection limit of the test was $5 \mathrm{fg}$ of pure T. brucei DNA; one parasite in $180 \mu \mathrm{l}$ of blood is still detectable. The authors concluded that HAT-PCR$\mathrm{OC}$ is a promising new tool for diagnosis of "sleeping sickness" in laboratory settings.

Nanogold chemoterapy

Nyarko et al. [32] described the effects of aqueous Au(III) and his metalloporphyrin derivative on T. brucei brucei growth in culture. While $\mathrm{Au}$ (III) porphyrin was effective against the parasites at concentrations above $4.8 \times 10^{-6} \mathrm{M}$, aqueous $\mathrm{Au}(\mathrm{III})$ ion was toxic to the trypanosomes at concentrations as low as $2.0 \times$ $10^{-7} \mathrm{M}$, due to free radicals formation. Although the parasite tested is responsible for an animal African trypanosomiasis (and this review deals mainly with human tropical diseases), the work of Nyarko et al. shows that gold might have a promising role in the battle against these noxious organisms.

A series of seven papers regarding metal-based chemotherapy against tropical diseases was published by SánchezDelgado and co-workers [33-39], from 1993 to 2004. Navarro, who wrote a very interesting review in 2009 about 
gold complexes as potential anti-parasitic agents [40], published since 1997, together with different co-workers, also some papers in this series [35, 36, 38, 39]. In one of those publications [36], the authors dealt with a group of metalclotrimazole complexes evaluating their activity against T. cruzi, including $\mathrm{AuCl}_{3}$ (clotrimazole). The clotrimazole (CTZ) is an azole derivative, and this family of compounds has been developed as chemotherapeutic agents for the treatment of fungal diseases on the basis of their properties as sterol biosynthesis inhibitors, which can also affect some parasites [36]. This $\mathrm{AuCl}_{3}(\mathrm{CTZ})$ complex (Fig. 3, middle) showed an anti-T. cruzi epomastigotes activity only slightly higher than the free CTZ (60\% vs. $58 \%$ ), with a poor performance compared other metal-CTZ complexes [36, 40]. In another paper [38], Navarro et al. considered other azol derivative (ketoconazole [KTZ]) and other Au precursor, preparing $\left[\mathrm{Au}(\mathrm{CTZ})\left(\mathrm{PPh}_{3}\right)\right] \mathrm{PF}_{6}$ (Fig. 3, top) and $\left[\mathrm{Au}(\mathrm{KTZ})\left(\mathrm{PPh}_{3}\right)\right] \mathrm{PF}_{6} \cdot 2 \mathrm{H}_{2} \mathrm{O}$ (Fig. 3, bottom) complexes. Both complexes $(1 \mu \mathrm{M})$ showed an inhibition of the proliferation of the $T$. cruzi epimastigotes around $70 \%$, while the free CTZ has no effect on the growth and KTZ only inhibited $39 \%$ at the same concentration [38, 40].

It is also important to mention the role of gold in biolistic (or biological ballistics, consisting in transfecting cells by bombarding them with microprojectiles coated with DNA) immunization using a stable DNA-gold precipitate [41]. As the target population of a $T$. cruzi vaccine lives predominately in poorer rural areas in South America, the use of such DNA-gold precipitate, which does not require a cold chain, is an attractive method for vaccination.

\section{Leishmaniasis}

About the disease

Some Leishmania parasitic protozoa are the cause of leishmaniasis in humans. The disease is spread through the bite of phlebotomine sandflies, which breed in forest areas, caves and adobe brick houses, where most of the transmission to humans takes place. This disease can be divided in four main types [3]:

(1) Cutaneous forms, with skin ulcers usually on exposed areas, such as the face, arms and legs, that usually heal within a few months, but leaving scars.

(2) Diffuse cutaneous leishmaniasis, which produce disseminated and chronic skin lesions and it is difficult to treat.

(3) Mucocutaneous forms, where the lesions can destroy the mucous membranes of the nose, mouth, throat cavities and surrounding tissues.

(4) Visceral leishmaniasis (VL), which is characterized by high fever, considerable weight loss, anemia,

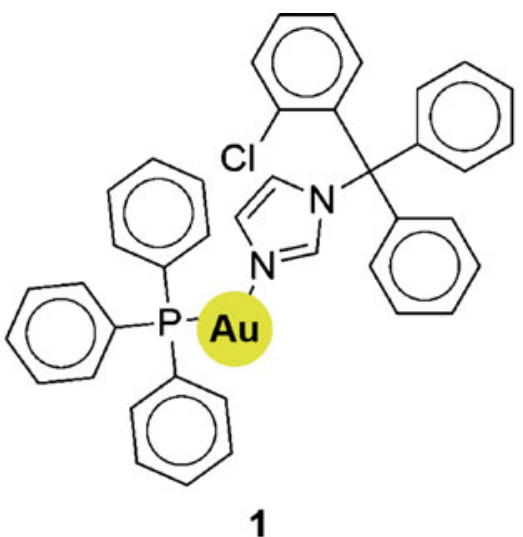<smiles></smiles>

2

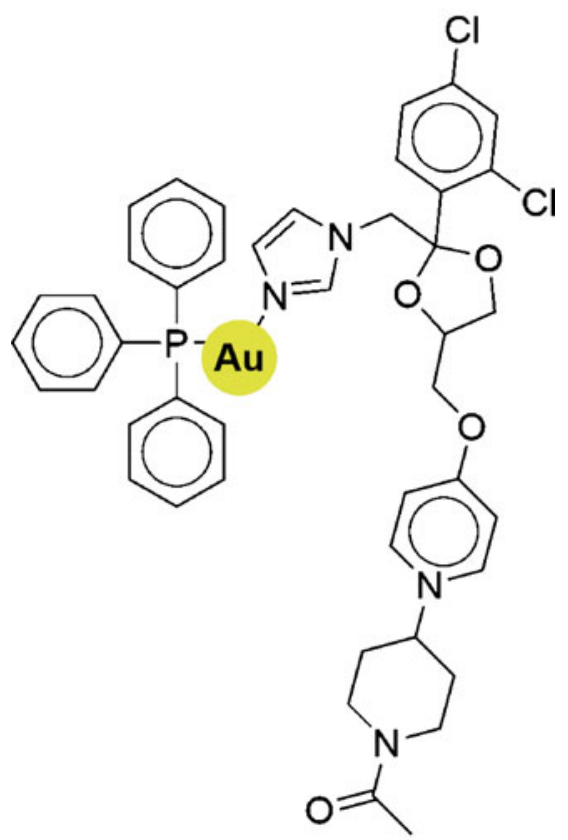

3

Fig. 3 Au ${ }^{\mathrm{I}}$-clotrimazole (1), $\mathrm{Au}^{\mathrm{III}}$-clotrimazole (2) and $\mathrm{Au}^{\mathrm{I}}$-ketoconazole (3) complexes (adapted from [40], counterions omitted for simplification)

spleen and liver swelling. If not treated, the disease can have a fatality rate, as high as $100 \%$, within 2 years. 
Microscopy assays using nanogold

Santos et al. [42], in 1991, used transmission electron microscopy for observation of lectins associated with colloidal gold particles $(15 \mathrm{~nm})$. AuNP bound to concanavalin A (a lecitin protein) were found randomly and sparsely distributed on the Leishmania donovani chagasi surface, along the cell body and along the flagellum. The pre-treatment of promastigotes of with trypsin did not interfere with the binding of lectins to the parasite or alter the parasite ultrastructure, showing a good resistance to this protease. However, a pre-treatment with 2-mercaptoethanol increased the colloidal gold density, showing that this last compound exposed second-order concanavalin A receptors.

The intracellular fate of human transferrin (HTf) in macrophages infected by Leishmania was investigated by Borges et al. [43], i.e., binding the HTf to gold nanoparticles complexes for further observation in order to understand the location and processing of HTf across time. Within parasites, HTf was found in cysteineproteinase-rich structures, suggesting that the protein can be endocytosed by intracellular amastigotes and sorted to the parasite endosomal-lysosomal compartments rather than being recycled.

Sengupta et al. [44] explored the relation between hemoglobin endocytosis and the parasite, using immunogold techniques, contributing to understand the hemoglobin destruction, a critical aspect in the disease. A specific high affinity binding site on the surface of Leishmania donovani promastigotes mediated rapid internalization and degradation of hemoglobin. When Leishmania, previously incubated with hemoglobin at $4{ }^{\circ} \mathrm{C}$, were treated with a rabbit anti-hemoglobin antibody, followed by an anti-rabbit IgG conjugated with colloidal gold, accumulation of gold particles could be seen in the flagellar pocket. After incubation with hemoglobin-gold conjugates at $25{ }^{\circ} \mathrm{C}$ or $37{ }^{\circ} \mathrm{C}$, the particles accumulated in discrete intracellular vesicles, suggesting the internalization of hemoglobin at both temperatures. Quantitation could be carried out by counting the number of gold particles internalized by Leishmania for each set of experimental conditions.

Detection methods using nanogold

Zijlstra et al. [45] evaluated a strip test employing recombinant K39 (rK39) antigen and protein-A (a surface protein originally found in the cell wall of the bacterium Staphylococcus aureus)/colloidal gold as read-out agents. They stated that this test has the ideal format for use in the field but also has important limitations and should be used with caution. In general, a positive test result in a patient who presents with the classical clinical features of VL supports the diagnosis. It should be noted that a positive test result may be the result of previous (subclinical) infection and therefore not relevant to the current illness. Under field conditions, it is not always clear from the history whether a patient who reports previous treatment for VL was correctly diagnosed at the time. Such test was used recently by Carreira et al. [46] in order to study the natural infection with Leishmania infantum on opossums (Didelphis aurita), considered natural hosts of parasites, suggesting their important role in the epidemiology of VL. This work allowed the authors to present the first report of amastigotes in the tissues of Didelphis aurita naturally infected with $L$. infantum.

Ramos-Jesus and co-workers [47] prepared a quartz crystal gold electrode where the recombinant antigen of Leishmania chagasi rLci2B-NH6 was tightly immobilized on a quartz crystal gold electrode by self-assembled monolayer based on short-chain length thiol. This device was planned for the canine visceral form; however this assembling seems to be promising also for human leishmaniasis. It is important to distinguish from the similar examples given before [27, 28], as no immunotechnique is applied to sensor construction in this case. The amine groups of cysteamine provided reaction sites for covalently bind to the glutaraldehyde. The rLci2B-NH6 antigen was then immobilized through a Schiff base via glutaraldehyde by a histidine tail (Fig. 4). The Schiff base allows major exposure of epitopes and a reduced steric hindrance. The response was obtained by recognition of immobilized rLci2B-NH6 antigen.

Moreno et al. [48] designed a novel SELEX procedure (a methodology in which single stranded oligonucleotides are selected from a wide variety of sequences based on their interaction with a target molecule) using colloidal gold to select high affinity single stranded DNA aptamers that bind specifically to $L$. infantum KMP-11. Kinetoplastid membrane protein-11 (KMP-11) is a major component of the cell

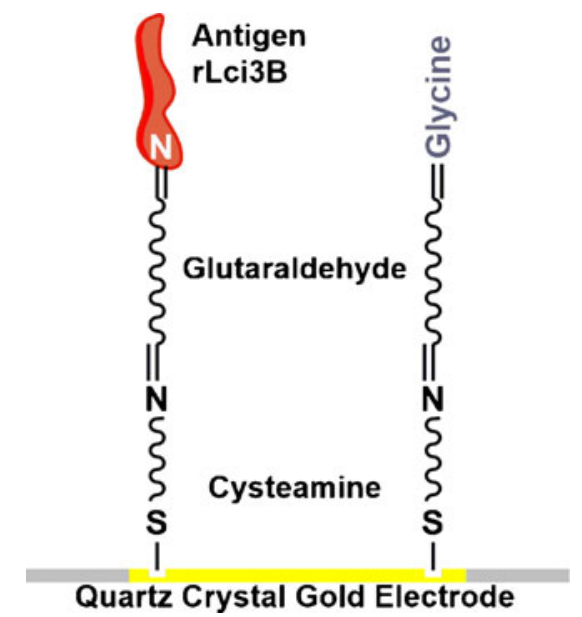

Fig. 4 Quartz crystal gold electrode supporting rLci3B-NH6 via cysteamine and glutaraldehyde (adapted from [47]). Glycine presence represents the blocking treatment in order to minimize the nonspecific binding 
membrane of kinetoplastid parasites. Although its function is not known, the fact that KMP-11 is a cytoskeletonassociated protein suggests that it may be involved in mobility or in some other aspects of the flagellar structure. The method is based on the binding of the target protein to colloidal gold in order to achieve a higher amount of that protein for further purification by centrifugation. This novel methodology is very easy to use and cheaper than others that are currently being used. The same authors also developed an electrochemical biosensor based on aptamers that can recognize and specifically report the presence of $L$. infantum KMP-11. The target protein was conjugated with gold nanoparticles and the complexes electrodeposited on gold screen-printed electrodes (SPE) [49]. Using this method, Moreno et al. were able to detect $25 \mathrm{mg} / \mathrm{ml}$ of KMP-11.

Nanogold chemotherapy and thermotherapy

Recently, Ilari et al. [50] reported on the interesting antiparasitic actions of a well-known antiarthritic agent, the gold(I)-containing drug Auranofin. As trypanothione reductase, a key enzyme of $L$. infantum, contains a dithiol motif at its active site and gold(I) compounds are known to be highly thiophilic, it was found that Auranofin behaved as an effective enzyme inhibitor. It might also be a potential antileishmanial agent, as it was also found that Auranofin is able to kill the promastigote stage of $L$. infantum at micromolar concentration. These important findings will certainly contribute to the design of new drugs against this disease.

Navarro et al. [51] studied a gold complex prepared from a dypirido[3,2- $a$ : $2,3-c]$ phenazine ligand, $\left[\mathrm{Au}(\mathrm{dppz})_{2}\right] \mathrm{Cl}_{3}$ (Fig. 5), that interacts with DNA by intercalation mode. The large leishmanicidal activity of this complex was associated to the cellular processes involving parasite DNA, constituting a new promising chemotherapeutic alternative in the search for the cure of leishmaniasis [51].

More recently, Barboza-Filho et al. [52] studied the growth of Leishmania brasiliensis promastigotes in culture, using natural rubber membranes with and without gold nanoparticles. It was observed that the increase of AuNP caused a decrease in the number of promastigotes

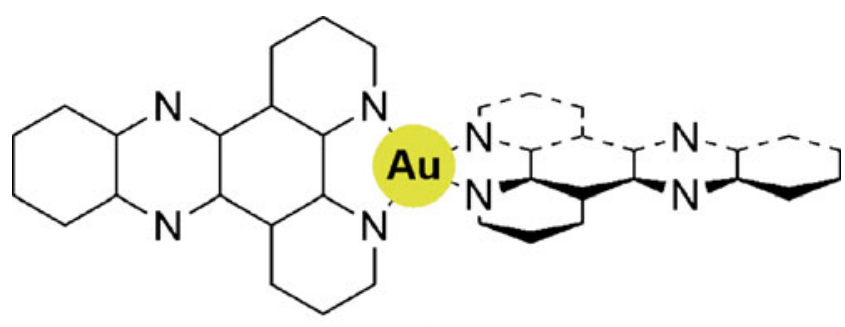

4

Fig. 5 Complex prepared by Navarro et al. from dypirido[3,2-a: 2,3-c] phenazine ligands (perpendicular to each other) (adapted from [51]) in culture medium. These results are advanced as a possible solution for developing a flexible "band-aid" for skin lesions, inhibiting the population growth of parasites in the lesions.

A recent study from Sazgarnia et al. [53] determined the efficacy of thermotherapy in the presence of AuNP and microwave radiation $(2,450 \mathrm{MHz})$ on the survival of Leishmania major promastigotes and amastigotes. It was shown that the presence of AuNP during microwave irradiation (after cell incubation) was more lethal for promastigotes and amastigotes when compared to microwave radiation alone. This shows that AuNP are a promising new approach to treat leishmaniasis in the future.

\section{Malaria}

About the disease

Malaria is caused by the Plasmodium parasite, which is transmitted through the bites of infected mosquitos. After entering in the human body, the parasites multiply in the liver and infect the red blood cells. Fever, headache, and vomiting are symptoms of malaria and usually appear between 10 and 15 days after the mosquito bite. Malaria can quickly become life-threatening by disrupting the blood supply to vital organs and, in many parts of the world, the parasites have developed resistance to a number of known medicines. About 3.3 billion people (almost half of the world's population) are at risk of getting malaria. Every year, this leads to about 250 million cases and nearly 1 million deaths. Consequently, a prompt and effective treatment is crucial [4].

\section{Microscopy assays using nanogold}

In the study performed by Bhowmick et al. [54], immunogold electron microscopy was used for sub-cellular localization of Plasmodium falciparum enolase. This protein was detected at every stage of the parasite life cycle, in cytosol (the liquid found inside cells) and associated with nucleus, food vacuole (storage membrane bound organelle), cytoskeleton and plasma membrane. Diverse localization of enolase suggests that apart from catalysing the conversion of 2-phosphoglyceric acid into phosphoenolpyruvate in glycolysis (its typical role in cytosol), it may also be involved in other functions, namely, in red blood cell invasion, food vacuole formation and/or development and transcription. These new data seems to clarify the role of this enzyme in the parasite life.

The work of Chugh et al. [55], helped to determine the reasons why two monoclonal antibodies (AC-43 and AC- 
29) significantly inhibited Plasmodium vivax development inside the mosquito Anopheles culicifacies midgut (a portion of insect's digestive system). The gold labeling showed that these two monoclonal antibodies bind to glycoproteins present in the gut epithelium (intestine wall), a known zone for its ookinetes receptors (receptors of the fertilized zygote of the parasite in the mosquito's body), which assures the crossing of the epithelial barrier and provide components for further development into oocysts (the encysted or encapsulated ookinetes in the mosquito's inside). These data point to these glycoproteins as potential candidates for a vectordirected transmission-blocking vaccine, stopping the parasite cycle in the ookinetes-oocysts transition step.

Recently, Lopes da Silva et al. [56] used bovine serum albumin (BSA) linked to $10 \mathrm{~nm}$ AuNP in order to follow their position in the parasite-host cell system, in the liver stage, a crucial phase of the Plasmodium development. The authors showed that when BSA-Au are loaded into the host cell endocytic pathway, the AuNP are later found within the parasite cytoplasm, showing the transport of materials from the host endocytic pathway towards the parasite interior, revealing a possible form of the parasite to obtain nutrients.

\section{Detection methods using nanogold}

Stevens et al. [57] described a different approach using AuNP. The Immunoglobulin M (IgM) antibody bounded to the assay membrane acts as the capture molecule. The gold-antibody conjugate acts as the label, generating a visible increase in optical density proportional to the concentration of analyte present, that is, the malarial antigen P. falciparum histidinerich protein II (PfHRP2). If this antigen (which acts as a bridge between the membrane-IgM and $\mathrm{Au}-\mathrm{IgG}$ systems) is not present, $\mathrm{Au}-\mathrm{IgG}$ will disappear after washing and no changes in optical density will be observed. A positive test is schematized in Fig. 6.

Amperometric immunosensors can also be used for monitoring this disease. Sharma et al. [58] presented recently a sensor based on AuNP/alumina sol-gel modified SPE for antibodies to PfHRP2. The AuNP electrode $\left(\mathrm{AuNP} / \mathrm{Al}_{2} \mathrm{O}_{3}\right.$ sol-gel/SPE) had much larger amperometric current $(390 \mathrm{nA})$ than the bare SPE $(120 \mathrm{nA})$ and $\mathrm{Al}_{2} \mathrm{O}_{3}$ sol-

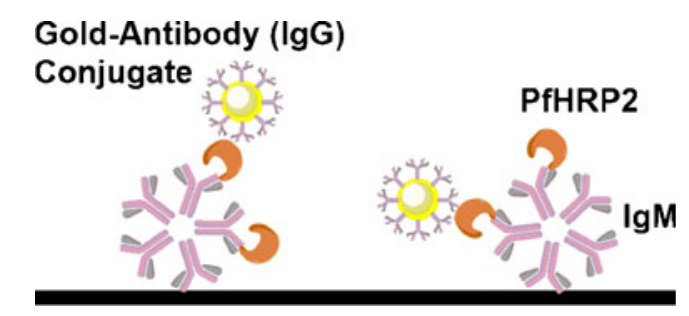

Fig. 6 PfHRP2 positive assay (adapted from [57])
gel/SPE (154 nA). AuNPs $/ \mathrm{Al}_{2} \mathrm{O}_{3}$ sol-gel/SPE was three times more sensitive compared to unmodified/bare SPE for the same concentration of analyte. Recently, Fu et al. [59] developed a device consisting on a two-dimensional paper network signal-amplified immunoassay for malaria protein PfHRP2 detection. The paper card contains reagents stored in dry form, including an antibody conjugated to a gold particle label, and the user only needs to add water and the sample. Factors like the signal/noise ratio and test sensitivity are always a concern with AuNP based (and other) tests. Therefore, improvements in this area are also important, besides the test principle itself, as demonstrated for the PfHRP2 malaria biomarker [60].

Potipitak et al. [61] created a device specifically for $P$. falciparum that can be adapted for other parasites. A biotinylated probe was linked to the gold electrode of quartz crystal microbalance (QCM) surface based on the specific interaction between avidin protein and biotin (vitamin B7). Prior to this immobilization, the QCM surface was pre-treated (e.g., with MPA) to add the ester group on the surface, in order to bind with the amine group of avidin. This technique was based on DNA piezoelectric biosensor using the Au electrode of QCM. The deposited mass, due to DNA hybridization on the QCM surface, resulted in a shift of the quartz resonance frequency. Moreover, the new sensor is cost-effective since both sides of the quartz Au surface can be used separately, reducing the sensor price to $50 \%$.

Very recently, Guirgis et al. [62] described a homogeneous assay based on the fluorescence quenching of cyanine 3B (Cy3B)-labeled recombinant $P$. falciparum heat shock protein 70 (PfHsp70) upon binding to AuNP functionalized with an anti-Hsp70 monoclonal antibody. Upon competition with the free antigen, the Cy3Blabeled recombinant PfHsp70 is released to solution resulting in an increase of fluorescence intensity. Concerning test kits involving colloidal gold, Piper et al. [63] recently showed that a panel of monoclonal antibodies against Plasmodium lactate dehydrogenase can be used in various combinations to uniquely identify all species of malaria parasites that infect humans. Their results should help the development of new test with greater specificity, sensitivity and ability to differentiate among malaria parasite species, adding to some solutions already in the market [64].

Nanogold chemoterapy

Concerning antimalarial gold compounds, and in context of the already mentioned series of seven papers related to metal-based chemotherapy against tropical diseases [33-39], Navarro et al. described the reaction of $\mathrm{AuPPh}_{3} \mathrm{Cl}$ with chloroquine (CQ) and $\mathrm{KPF}_{6}$ leading to the new 
complex $\left[\mathrm{Au}\left(\mathrm{PPh}_{3}\right)(\mathrm{CQ})\right] \mathrm{PF}_{6}$. This compound was found to be considerably more active than CQ diphosphate and other previously reported metal-CQ complexes ( $\mathrm{Ru}$ or $\mathrm{Rh}$ [34]) against two chloroquine-resistant strains of $P$. falciparum in vitro [35]. Navarro et al. also prepared a series of new $\mathrm{Au}(\mathrm{I})$ and $\mathrm{Au}$ (III) complexes containing CQ in combination with other ligands, which display activity against CQ-sensitive but also against CQ-resistant strains of P. falciparum [39]. The highest activity for this series was obtained for $\left[\mathrm{Au}(\mathrm{CQ})\left(\mathrm{PEt}_{3}\right)\right] \mathrm{PF}_{6}$. More recently, Navarro et al. [65] studied the mechanism of antimalarial action of $\left[\mathrm{Au}(\mathrm{CQ})\left(\mathrm{PPh}_{3}\right)\right]$ $\mathrm{PF}_{6}$. This compound seems to avoid heme aggregation (which allows accumulation of toxic levels of compound, resulting in parasite death). The high activities observed against parasites resistant to chloroquine are probably due to the structural modification of CQ introduced by the presence of the gold-triphenylphosphine fragment. The scheme of these complexes can be found in Fig. 7.

Blackie et al. [66] described the synthesis of $\left[\mathrm{Au}(\mathbf{R})\left(\mathrm{PPh}_{3}\right)\right]$ $\mathrm{NO}_{3}$ and $\left[\mathrm{Au}\left(\mathrm{C}_{6} \mathrm{~F}_{5}\right)(\mathbf{R})\right]$ complexes, where $\mathbf{R}$ denotes a CQ group or a ferrocenyl-4-amino-7-chloroquinoline, and their use as anti-malarial agents. Rh complexes were also tested. The CQ complexes showed better efficacy against CQresistant strains of the P. falciparum when comparing to free CQ. For the CQ-resistant strain, there is a considerable drop in efficacy. Concerning to the compounds with the ferrocenyl-4amino-7-chloroquinolines, those containing ferroquine were considered the most efficient, but all showed improved efficacy with respect to CQ in both sensitive and resistant strains.

Fricker et al. [67] used a set of six Au(III) complexes, showing that all of them were able to inhibit cathepsin B, with a half maximal inhibitory concentration $\left(\mathrm{IC}_{50}\right)$ values in the range of $0.2-1.4 \mu \mathrm{M}$. Cysteine proteases cathepsin B play multiple roles in the parasite life cycle like nutrition, host invasion, protein processing, and evasion of the host immune response, so their inhibition can be extremely important.

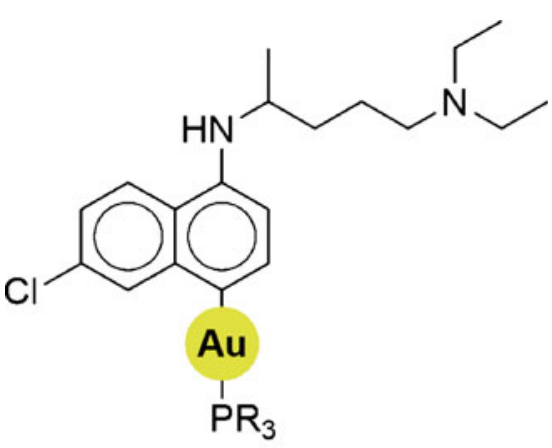

5

Fig. $7\left[\mathrm{Au}\right.$ (chloroquine) $\left.\left(\mathrm{PR}_{3}\right)\right] \mathrm{PF}_{6}$ complexes $(\mathrm{R}=\mathrm{Me}, \mathrm{Et}$ or $\mathrm{Ph})$ prepared by Navarro et al. (adapted from [39, 65])
Also well-known gold-based drugs like Auranofin (the antiarthritic medicine that also demonstrated potential antileishmanial activity, as referred above), showed recently very pronounced antiplasmodial effects in vitro [68]. Auranofin proved to be a potent inhibitor of mammalian thioredoxin reductases causing severe intracellular oxidative stress. Given the high sensitivity of $P$. falciparum to oxidative stress, the authors thought that Auranofin might act as an effective antimalarial agent and showed that this compound (and a few other related gold complexes) strongly inhibits $P$. falciparum growth in vitro.

Recently, Bjelosevic et al. [69] prepared a set of gold(I) complexes based on 1,10-bis(diphenylphosphino) metallocene derivatives (Fig. 8) and evaluated their activity against malaria (W2 chloroquine-resistant strain of $P$. falciparum) and other diseases. Although the $\mathrm{IC}_{50}$ values (half-maximal inhibitory concentrations, which indicate how much are needed to induce inhibitions of $50 \%$ ) are low, they are still much higher than those for chloroquine. The biological activities of ruthenocenylbased gold compounds are superior to their ferrocenyl analogues and thus provide directions as to which of these ligands can be used for medicinal applications.

Very recently, Hemmert et al. [70] described the use of gold(I) and gold(III) complexes with $N$-heterocyclic carbene (NHC) ligands as antimalarial agents, specifically against the chloroquine-resistant $P$. falciparum strain FcM29Cameroon. A group of four dinuclear gold(I) complexes plus three dinuclear gold(III) complexes (Fig. 9, top) was studied, followed by another group of three mononuclear gold(I) complexes (Fig. 9, bottom). The gold(I) dinuclear complexes were found to have moderate antimalarial effect $\left(\mathrm{IC}_{50}\right.$ never lower than $9 \mu \mathrm{M}$ ), but less efficient than the silver(I) counterparts. However, all gold complexes were found to not cause hemolysis (red blood cells membrane bursting with subsequent release of hemoglobin), in contrast to some of the silver analogues. The second group of gold complexes (mononuclear gold(I)) revealed an improved

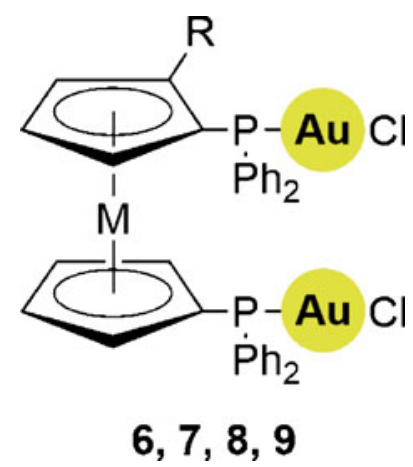

Fig. $8 \mathrm{Au}^{\mathrm{I}}$ complexes based on metallocene derivatives prepared by Bjelosevic et al. and tested as antimalarial agents $(\mathbf{6}: \mathrm{M}=\mathrm{Ru}, \mathrm{R}=$ $\mathrm{CHCH}_{3} \mathrm{~N}\left(\mathrm{CH}_{3}\right)_{2} ; 7: \mathrm{M}=\mathrm{Fe}, \mathrm{R}=\mathrm{CHCH}_{3} \mathrm{OCOCH}_{3} ; \mathbf{8}: \mathrm{M}=\mathrm{Ru}, \mathrm{R}=$ $\mathrm{CHCH}_{3} \mathrm{OCOCH}_{3} ;$ 9: $\left.\mathrm{M}=\mathrm{Ru}, \mathrm{R}=\mathrm{CHCH}_{3} \mathrm{NHCO}\left(\mathrm{CH}_{2}\right)_{2} \mathrm{COOH}\right)$ (adapted from [69]) 


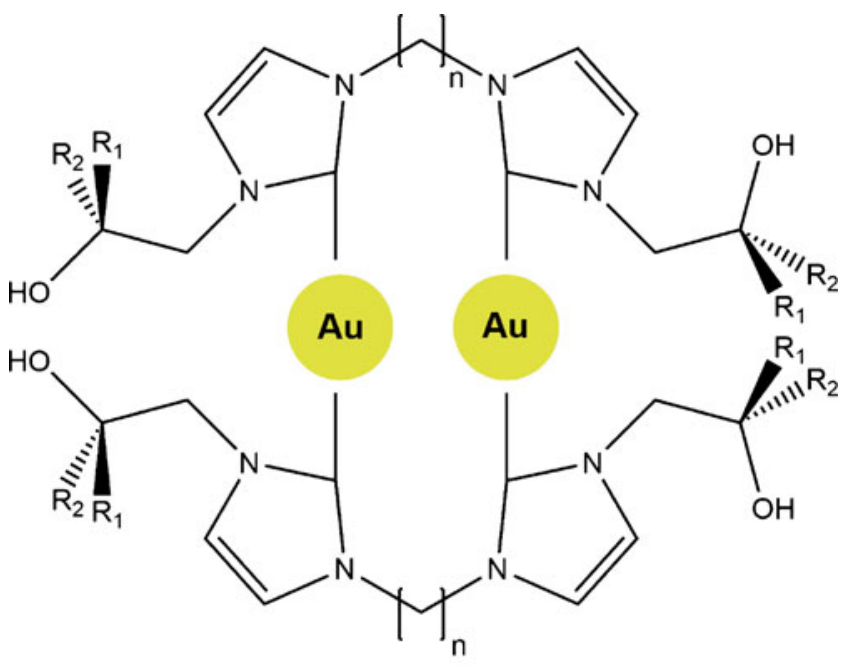

$10,11,12,13,14,15,16$

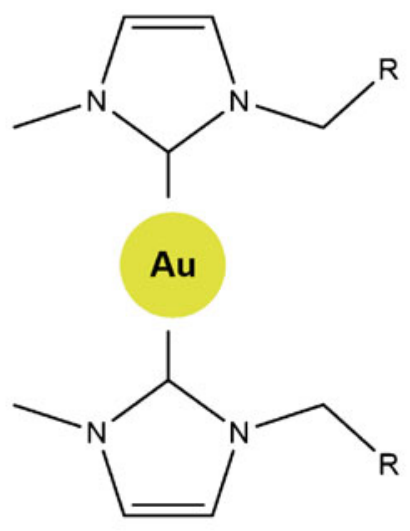

$17,18,19$

Fig. 9 Dinuclear $\mathrm{Au}^{\mathrm{I}}\left(\mathbf{1 0}: n=1, \mathrm{R}_{1}=\mathrm{R}_{2}=\mathrm{CH}_{3} ; 11: n=2, \mathrm{R}_{1}=\mathrm{R}_{2}=\mathrm{CH}_{3}\right.$; 12: $\left.n=2, \mathrm{R}_{1}=\mathrm{Ph}, \mathrm{R}_{2}=\mathrm{H} ; 13: n=3, \mathrm{R}_{1}=\mathrm{Ph}, \mathrm{R}_{2}=\mathrm{H}\right)$, dinuclear $\mathrm{Au}^{\text {III }}(\mathbf{1 4}$ : $\left.n=1, \mathrm{R}_{1}=\mathrm{R}_{2}=\mathrm{CH}_{3} ; 15: n=2, \mathrm{R}_{1}=\mathrm{Ph}, \mathrm{R}_{2}=\mathrm{H} ; 16: n=3, \mathrm{R}_{1}=\mathrm{Ph}, \mathrm{R}_{2}=\mathrm{H}\right)$ and mononuclear $\mathrm{Au}^{\mathrm{I}}(17: \mathrm{R}=\mathrm{CONHPh}$; 18: $\mathrm{R}=$ quinoline; 19: $\mathrm{R}=$ 2,2'-bipyridine) complexes (adapted from [70]). Note: for simplicity, the following are omitted in the figure: two $\mathrm{PF}_{6}{ }^{-}$counterions for each one of the 10-16 complexes, two $\mathrm{Br}$ atoms coordinated to each $\mathrm{Au}$ atom for the complexes 14-16 and one $\mathrm{Cl}^{-}, \mathrm{PF}_{6}{ }^{-}$or $\mathrm{Br}^{-}$counterion for complexes $\mathbf{1 7 - 1 9}$, respectively

performance compared to the first group, achieving $\mathrm{IC}_{50}$ values as low as $0.33 \mu \mathrm{M}$ for one of the compounds.

Soni and Prakash [71] described the larvicidal effect of AuNP (synthesized using biomass derived from the Chrysosporium tropicum fungus and $\mathrm{HAuCl}_{4}$ ) against Anopheles stephensi larvae, a primary mosquito vector of malaria. The exposure to AuNP solutions can lead up to $100 \%$ mortality, depending on the larval instar (developmental stage). Although this study is not a therapy protocol for the disease itself, the larvicidal effect obtained is significant and can lead a better, environmentally safer and greener approach to control this malaria vector in early stages.

\section{Dengue}

About the disease

Dengue is a febrile illness that affects infants, young children and adults, in tropical and sub-tropical areas of the world. It is transmitted through the bite of an Aedes mosquito, infected with any of the four types of dengue viruses. The symptoms include fever, with severe headache, pain behind the eyes, muscle and joint pain, and rash. They usually appear 3 to 14 days after the insect bite. Severe dengue (plasma leakage, strong hemorrhages, organ failure) is a potentially lethal complication, affecting both children and adults. Naturally, early clinical diagnosis can increase survival of patients [5].

Microscopy assays using nanogold

The reports on the use of microscopy in connection with nanogold, dealing with dengue virus itself, are scarce, probably due to the viral nature of the pathogen, in contrast to the cellular protozoans agents of the other diseases described above. Two works, performed about two decades ago, used immunogold applied to intracellular localization of a dengue antigen:

Thet and Thein [72] showed the potential use of proteinA-Au complex as a marker in the detection of dengue antigen by immunogold labeling for light microscopy. Dengue 4 prototype virus $\mathrm{H} 241$, propagated in $\mathrm{C} 6 / 36$ mosquito cell cultures, was used for in vitro experiments. The dengue antigen was detected by using polystyrene beads coated with anti-dengue $\mathrm{IgG}$. The presence of dengue antigen was shown by the formation of pink color (seen with the naked eye) on the beads when incubated with antigen, antibody and protein-A-Au complex. The intensity of the pink color was found to increase with the degree of infection on the infected coverslip cultured cells. The results obtained demonstrated that the use of the protein-A-Au complex had increased sensitivity and was able to detect antigen in the tissue culture at the post infection as early as the first day.

Chen et al. [73] also used immunogold labeling, emphasizing its high sensitivity. A protein- $\mathrm{A}-\mathrm{Au}-\mathrm{Ag}$ staining was used to detect the virus antigens in cultured dengue inoculated C6/36 clone of Aedes albopictus cells and human endothelial cells. Data from direct immunofluorescence antibody (DFA) test were compared to immunogold labeling. The study revealed that all DFA-positive specimens were also found positive for immunogold labeling, but not vice versa. This showed that the method using nanogold was more sensitive than DFA.

In a recent study, Vancini et al. [74] analysed the early events in the infection process of dengue and other Flavivirus, using electron microscopy and immunogold labeling of viral particles during cell entry. The obtained data supports 
the hypothesis of cells infection by a mechanism that involves direct penetration of the host cell plasma membrane.

Detection methods using nanogold

Like in other biosensors described for the previously mentioned diseases, gold can be in the bulk (surface) form, being a support for the sensor assembling active part, as described by Kumbhat et al. [75] for serological diagnosis of dengue virus infection, using surface plasmon resonance (SPR) as analytical technique.

Gold can also be in the form of nanoparticles, as in the following examples: Hsu and co-workers [76] described a sensitive AuNP based inductively coupled plasma mass spectrometry (ICP-MS) amplification and magnetic separation method for the detection of oligonucleotide virusspecific RNA sequences. There is a sandwich-type binding of two designed probe sequences (as illustrated in Fig. 10) that specifically recognize the target regions. They have attached (1) magnetic beads for easy separation and (2) AuNP based beads for ICP-MS amplification detection. Compared with the standard methodology (plaque assay) for the quantification of dengue, the method described allows early detection of the virus in complicated and smallvolume samples, with high specificity, good analytical sensitivity, and superior time-effectiveness. The process can be described in five main steps: (1) virus lysing, (2) incubation with magnetic probe and washing, (3) incubation with AuNP probe and washing, (4) releasing and dissolving AuNP for (5) ICP-MS analysis.

Nascimento et al. [77] described the preparation and characterization of a novel gold nanoparticle-polyaniline hybrid composite (AuNpPANI, schematized in Fig. 11), containing SH terminal groups with the ability of immobilizing dengue serotype-specific primers (ST1, ST2 and ST3). Electrochemical impedance spectroscopy (EIS) and cyclic voltammetry (CV) were performed. The authors showed that AuNpPANIST(1-3) systems (Fig. 12, left) are capable of detecting dengue serotypes with high specificity and reproducibility at picomolar concentrations. The AuNpPANI-ST system

\section{Target Region حn Virus RNA}

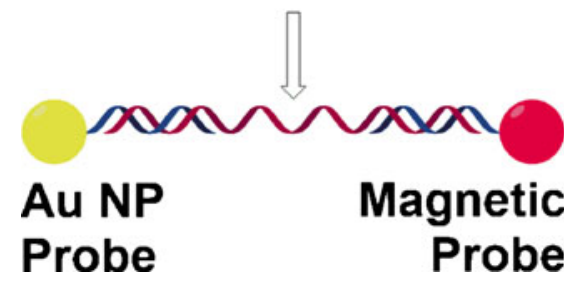

Fig. 10 Sandwich-type binding of two probes to the target region of the RNA virus (adapted from [76]) exhibited a highly selectivity response to the complementary target of human patient's dengue genome (Fig. 12, right). According to the authors, this can be a step in development of dengue serotype biosensors that are functional even in the presence of small volumes and low concentrations of the analyte. Even in those conditions, the CV and EIS results showed unequivocal evidence of an existing interaction between dengue serotype-specific primers and their complementary genomic DNA targets.

The dengue IgM capture ELISA is the immunoenzymatic system recommended by the Pan American Health Organization and the World Health Organization for the serological diagnosis of dengue virus infection, due to its high sensitivity, ease of performance, and use of a single acute-phase serum sample [78]. However, tests with the ELISA system are timeconsuming and require equipment for washing, incubation, and reading of the results. In 2003, Vazquez et al. [78] described the use of AuBioDOT, a multistep visual diagnostic immunoassay that uses technology based on the IgM capture ELISA principle. This system uses white polyethylene opaque plates as the solid phase, colloidal gold as the marker, and silver ion amplification. It does not require special equipment, it is totally manually operated, and it can be performed in less than $1 \mathrm{~h}$. The application of AuBioDOT for the detection of anti-dengue virus IgM antibodies is recommended as an alternative method for the diagnosis of dengue virus infection, both for clinical diagnosis and for seroepidemiological surveillance. The system is useful under field conditions and in laboratories and requires little equipment. The AuBioDOT IgM capture test for the detection of anti-dengue virus antibodies is a multistep immunoassay that uses manual operation, visual reading, and colloidal gold-labeled conjugated monoclonal antibodies. Colloidal AuNP were used to make a microfluidics-based bioassay that is able to recognize specific DNA sequences via conformational change-induced fluorescence quenching. In this method, a self-assembled monolayer of AuNP was fabricated on the channel wall of a microfluidic chip, and DNA probes were bonded to the monolayer via thiol groups. This test was applied for the detection of the PCR product of dengue virus and results indicate that the assay is specific for the target gene [79].

Oliveira et al. [80, 81] immobilized concanavalin A lecitin on gold electrode using AuNP and polyvinyl butyral and put the biosensor in contact to sera from patients infected by dengue. Changes passible to be detected by cyclic voltammetry and electrochemical impedance spectroscopy occurred.

As Foguel et al. [29] suggested for T. Cruzi detection, Cavalcanti et al. [82] also used a gold film electrode obtained from a recordable compact disk, but for the detection of non-structural protein 1 (NS1) of the dengue virus. This protein is abundantly present in blood during the acute phase of the dengue infection, in a correlation with viremia 
Fig. 11 Schematic representation of AuNpPANI synthesis (adapted from [77])

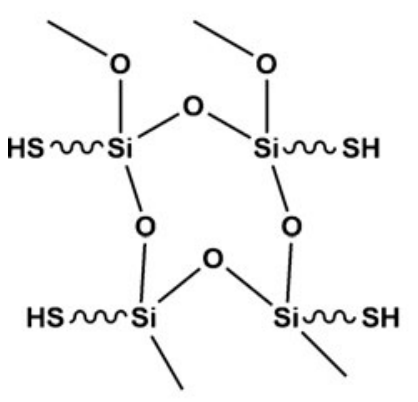

levels and, consequently, can be used to early diagnostic of the dengue hemorrhagic fever. These disposable gold electrodes with anti-NS1, successfully immobilized onto gold film surface via protein-A, present a high sensitivity (linear response from 1 to $100 \mathrm{ng}_{\mathrm{NS} 1} / \mathrm{ml}$ ) with a relatively low detection limit $\left(0.33 \mathrm{ng}_{\mathrm{NS} 1} / \mathrm{ml}\right)$ and selectivity in a electrochemical label-free detection technique. This same protein (NS1) was also the object of the study of Muller et al. [83], using microprojection arrays, a surface where are distributed micrometric cones or other shapes with sharp points, capable of easy skin penetration (with more than 20,000 projections $/ \mathrm{cm}^{2}$ ). They are usually applied to skin for the purpose of delivering high molecular weight compounds which cannot be delivered efficiently by other means, but used here for directly extracting circulating protein biomarkers from the skin. The use of gold on microprojection arrays deals with their coating in order to allow a better grafting (eventually with help of other small linking molecules) of biomolecules like anti-NS1 antibody for NS1 capture in the subject skin epithelia extracellular fluid. The detection of captured NS1 is made using an anti-NS1 antibody conjugated to HRP, using the principle described in Fig. 2, however with a support-antibody-antigen-antibody HRP assembling instead of the support-antigen-antibodyantibody HRP. This test surpasses others commonly used (like ELISA), which only accept serum/plasma samples, thus requiring significant laboratory-based processing and more invasive procedures for blood collecting.

There are other processes involving nanogold for dengue research and detection, but only slightly different than the several techniques already mentioned: Andrade et al. [84] showed an assembly consisting of a AuNpPANI on a gold

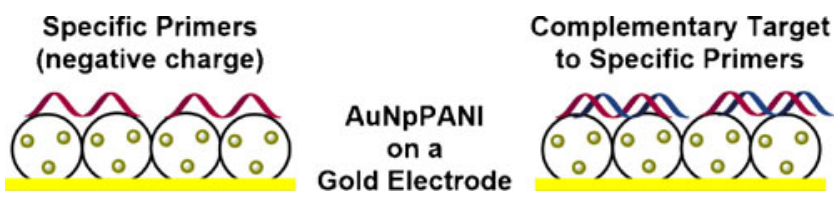

Fig. 12 Schematic representation the AuNpPANI on a gold electrode biosensor assembling (adapted from [77])
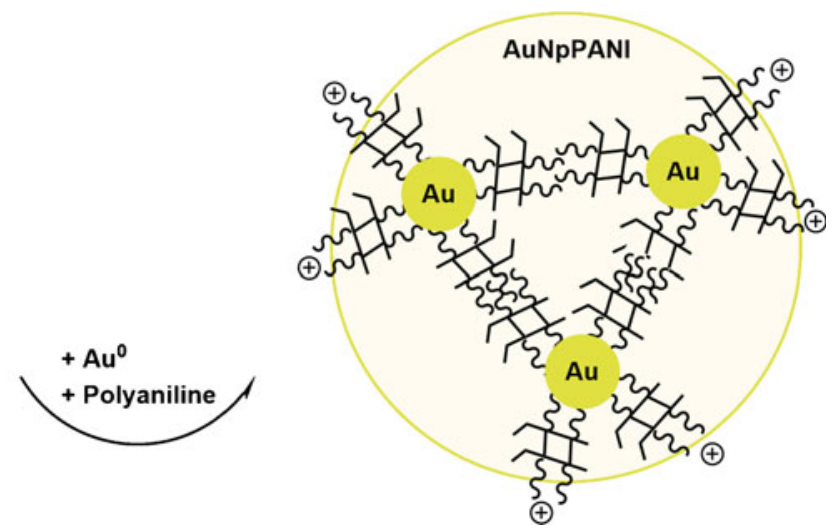

electrode, as already shown in Fig. 12; however, this system recognizes dengue glycoproteins instead of DNA specific regions. Chen et al. [85] used a QCM similar to a malaria test mentioned above, but supporting DNA dengue specific probes and also using a signal amplification technique with AuNP probes as those shown in Fig. 10. Oliveira et al. [86] also used the principles described in the last paragraph, but employed a different lecitin (from Cratylia mollis seeds) and $\mathrm{Fe}_{3} \mathrm{O}_{4}$ nanoparticles.

Unfortunately, until the time this review was written, to the best of our knowledge, there were no reports on the use of gold for dengue therapy, being this an important area of future research.

\section{Conclusions}

The results reported above strongly evidence the important role of gold in tropical diseases research. In terms of imaging, gold has high electron density which increases electron scatter enabling high contrast images, allowing a new understanding into the molecular immune pathogenesis of these maladies. Immunogold techniques contributed so far to understand the hemoglobin destruction, a critical aspect in the leishmaniasis disease, and also to the localization of an important malaria parasite protein. In terms of dengue, the combination of immunogold labeling and electron microscopy allowed the detection of virus antigens, and to obtain data supporting a mechanism of cells infection by direct penetration of the host cell plasma membrane.

To what concerns the detection of tropical diseases, important findings have also been achieved with gold. The research has been growing and several sensors can now assure easier diagnosis, namely in places where the comfort and resources of the laboratory are absent. As described above, gold can be in the bulk (surface) form, being a support for the sensor assembling active part, or in nanoparticles. Au electrodes showed advantages (as they are not influenced by oxygen dissolved in solution) for 
Chagas disease detection, compared to Pt analogues. For sleeping sickness, one parasite in $180 \mu \mathrm{L}$ of blood was still detectable in laboratory settings using gold as a colorimetric indicator, which is a remarkable result. Promising test kits using colloidal gold were reported for leishmaniasis and malaria. For the former, a novel cheaper and simplified SELEX procedure using colloidal gold has been reported. Interesting amperometric immunosensors containing gold were used for monitoring malaria. For dengue detection, a fast, fully manual, visual diagnostic immunoassay comprising the IgM capture ELISA principle, with colloidal gold as marker, was reported as an alternative to conventional ELISA systems, which are time-consuming and require a large quantity of equipment. The use of gold on microprojection arrays also surpasses ELISA. Several sensitive AuNP-based tests have also been reported for the efficient early detection of the dengue virus in complicated and small-volume samples.

In terms of disease therapy, gold complexes, like the antiarthritic drug Auranofin, showed potential antileishmanial and antimalarial activity. Other gold complexes are promising chemotherapeutic alternatives in the search for the cure of several tropical diseases, namely, $\mathrm{AuCl}_{3}(\mathrm{CTZ})$ against Chagas disease, $\left[\mathrm{Au}(\mathrm{dppz})_{2}\right] \mathrm{Cl}_{3}$ for leishmaniasis, $\left[\mathrm{Au}\left(\mathrm{PPh}_{3}\right)(\mathrm{CQ})\right] \mathrm{PF}_{6}$ and other $\mathrm{Au}(\mathrm{I})$ and $\mathrm{Au}(\mathrm{III})$ complexes containing CQ and NHC ligands for malaria. The latter were found to not cause hemolysis, in contrast to some silver analogues. AuNP also have been reported to have interesting roles in therapy, namely against Leishmania promastigotes in culture medium, becoming promising for flexible "band-aids" to be used skin lesions. AuNP also showed an interesting larvicidal effect for a mosquito vector of malaria, which can be a encouraging approach to control the malaria vector in early stages.

In terms of vaccines, the role of gold in biolistic immunization using a stable DNA-gold precipitate, not needing a cold chain, is also an attractive method for vaccination against Chagas disease in rural areas. Gold labeling showed that monoclonal antibodies bind to glycoproteins, pointing to these as potential candidates for a vector-directed transmissionblocking malaria vaccine, stopping the parasite cycle in the ookinetes-oocysts transition step.

After all that has been investigated on this topic, the overall conclusion is that the potential of gold for stimulating research in human tropical diseases is considerable. New results will certainly come out soon and lead to even more practical and commercial applications, the full extent of which has still to be envisaged.

Acknowledgments The authors are grateful to the financial support for this work provided by projects PTDC/QUI-QUI/100682/2008 and PEst-C/EQB/LA0020/2011 financed by FEDER through COMPETE, and by Fundação para a Ciência e a Tecnologia (FCT), and for CIENCIA 2007 program (for SACC).

Open Access This article is distributed under the terms of the Creative Commons Attribution License which permits any use, distribution, and reproduction in any medium, provided the original author(s) and the source are credited.

\section{References}

1. WHO (2012) TDR - Diseases and topics - African trypanosomiasis. http://www.who.int/tdr/diseases-topics/african-trypanosomiasis/ en/index.html. Accessed 20th August 2012

2. WHO (2012) TDR - Diseases and Topics - Chagas. http:// www.who.int/tdr/diseases-topics/chagas/en/index.html. Accessed 20th August 2012

3. WHO (2012) TDR - Diseases and topics - Leishmaniasis. http:// www.who.int/tdr/diseases-topics/leishmaniasis/en/index.html. Accessed 20th August 2012

4. WHO (2012) TDR - Diseases and topics - Malaria. http:// www.who.int $/ \mathrm{tdr} / \mathrm{diseases-topics/malaria/en/index.html.} \mathrm{Accessed}$ 20th August 2012

5. WHO (2012) TDR - Diseases and topics - Dengue. http:// www.who.int/tdr/diseases-topics/dengue/en/index.html. Accessed 20th August 2012

6. Bond GC, Louis C, Thompson DT (2006) Catalysis by gold, vol 6. Catalytic science series. Imperial College Press, London

7. Carabineiro SAC, Thompson DT (2007) Catalytic applications for gold nanotechnology. In: Heiz EU, Landman U (eds) Nanocatalysis. Springer-Verlag, Berlin, pp 377-489

8. Carabineiro SAC, Thompson DT (2010) Gold catalysis. In: Corti C, Holliday R (eds) Gold: science and applications. CRC Press, Taylor and Francis Group, Boca Raton, pp 89-122

9. de Almeida MP, Carabineiro SAC (2012) The best of two worlds from the gold catalysis universe: making homogeneous heterogeneous. ChemCatChem 4:18-29. doi:10.1002/cctc.201100288

10. Fricker SP (1996) Medical uses of gold compounds: past, present and future. Gold Bull 29:53-60

11. Bawarski WE, Chidlowsky E, Bharali DJ, Mousa SA (2008) Emerging nanopharmaceuticals. Nanomed Nanotechnol Biol Med 4:273-282. doi:10.1016/j.nano.2008.06.002

12. Boisselier E, Astruc D (2009) Gold nanoparticles in nanomedicine: preparations, imaging, diagnostics, therapies and toxicity. Chem Soc Rev 38:1759-1782. doi:10.1039/B806051G

13. Arvizo R, Bhattacharya R, Mukherjee P (2010) Gold nanoparticles: opportunities and challenges in nanomedicine. Expert Opin Drug Deliv 7:753-763. doi:10.1517/17425241003777010

14. Berners-Price SJ, Filipovska A (2011) Gold compounds as therapeutic agents for human diseases. Metallomics: Integr Biometal Sci 3:863-873. doi:10.1039/c1mt00062d

15. Hemphill A, Ross CA (1995) Flagellum-mediated adhesion of Trypanosoma congolense to bovine aorta endothelial cells. Parasitol Res 81:412-420. doi:10.1007/bf00931503

16. Abdo J, Kristersson T, Seitzer U, Renneker S, Merza M, Ahmed J (2010) Development and laboratory evaluation of a lateral flow device (LFD) for the serodiagnosis of Theileria annulata infection. Parasitol Res 107:1241-1248. doi:10.1007/s00436-010-1994-8

17. Alvarez I, Gutierrez G, Barrandeguy M, Trono K (2010) Immunochromatographic lateral flow test for detection of antibodies to Equine infectious anemia virus. J Virol Methods 167:152-157. doi:10.1016/j.jviromet.2010.03.026

18. Rassi A Jr, Rassi A, Marin-Neto JA (2010) Chagas disease. Lancet 375:1388-1402. doi:10.1016/S0140-6736(10)60061-X 
19. Magez S, Geuskens M, Beschin A, del Favero H, Verschueren H, Lucas R, Pays E, de Baetselier P (1997) Specific uptake of tumor necrosis factor- $\alpha$ is involved in growth control of Trypanosoma brucei. J Cell Biol 137:715-727. doi:10.1083/jcb.137.3.715

20. Soeiro MN, Paiva MM, Barbosa HS, Meirelles MN, Araújo-Jorge TC (1999) A cardiomyocyte mannose receptor system is involved in Trypanosoma cruzi invasion and is down-modulated after infection. Cell Struct Funct 24:139-149

21. Okuda K, Esteva M, Segura EL, Bijovsky AT (1999) The cytostome of Trypanosoma cruzi epimastigotes is associated with the flagellar complex. Exp Parasitol 92:223-231. doi:10.1006/ expr.1999.4419

22. Monteiro ACS, Abrahamson M, Lima A, Vannier-Santos MA, Scharfstein J (2001) Identification, characterization and localization of chagasin, a tight-binding cysteine protease inhibitor in Trypanosoma cruzi. J Cell Sci 114:3933-3942

23. Silva EO, Saraiva EMB, de Souza W, Souto-Padron T (1998) Cell surface characterization of amastigotes of Trypanosoma cruzi obtained from different sources. Parasitol Res 84:257-263. doi:10.1007/s004360050392

24. Acosta DM, Soprano LL, Ferrero M, Landoni M, Esteva MI, Couto AS, Duschak VG (2011) A striking common $O$-linked $N$ acetylglucosaminyl moiety between cruzipain and myosin. Parasite Immunol 33:363-370. doi:10.1111/j.1365-3024.2011.01291.x

25. Eger I, Soares MJ (2012) Endocytosis in Trypanosoma cruzi (Euglenozoa: Kinetoplastea) epimastigotes: visualization of ingested transferrin-gold nanoparticle complexes by confocal laser microscopy. J Microbiol Methods 91:101-105. doi:10.1016/ j.mimet.2012.07.013

26. Diniz FB, Ueta RR, Pedrosa AMD, Areias MD, Pereira VRA, Silva ED, da Silva JG, Ferreira AGP, Ferreira AGP, Gomes YM, Gomes YM (2003) Impedimetric evaluation for diagnosis of Chagas' disease: antigen-antibody interactions on metallic eletrodes. Biosens Bioelectron 19:79-84. doi:10.1016/s0956-5663(03)00213-6

27. Ferreira AAP, Colli W, da Costa PI, Yamanaka H (2005) Immunosensor for the diagnosis of Chagas' disease. Biosens Bioelectron 21:175-181. doi:10.1016/j.bios.2004.08.001

28. Ribone ME, Belluzo MS, Pagani D, Macipar MS, Lagier CM (2006) Amperometric bioelectrode for specific human immunoglobulin $G$ determination: optimization of the method to diagnose American trypanosomiasis. Anal Biochem 350:61-70. doi:10.1016/j.ab.2005.11.033

29. Foguel MV, dos Santos GP, Pupim Ferreira AA, Yamanaka H, Benedetti AV (2011) Amperometric immunosensor for Chagas' disease using gold CD-R transducer. Electroanalysis 23:25552561. doi:10.1002/elan.201100260

30. Pereira SV, Bertolino FA, Fernandez-Baldo MA, Messina GA, Salinas E, Sanz MI, Raba J (2011) A microfluidic device based on a screen-printed carbon electrode with electrodeposited gold nanoparticles for the detection of IgG anti-Trypanosoma cruzi antibodies. Analyst 136:4745-4751. doi:10.1039/c1an15569e

31. Deborggraeve S, Claes F, Laurent T, Mertens P, Leclipteux T, Dujardin JC, Herdewijn P, Buescher P (2006) Molecular dipstick test for diagnosis of sleeping sickness. J Clin Microbiol 44:2884 2889. doi: $10.1128 / \mathrm{jcm} .02594-05$

32. Nyarko E, Hara T, Grab DJ, Habib A, Kim Y, Nikolskaia O, Fukuma T, Tabata M (2004) In vitro toxicity of palladium(II) and gold(III) porphyrins and their aqueous metal ion counterparts on Trypanosoma brucei brucei growth. Chemico Biol Interact 148:19-25. doi:10.1016/j.cbi.2004.03.004

33. Sánchez-Delgado RA, Lazardi K, Rincón L, Urbina JA, Hubert AJ, Noels AN (1993) Toward a novel metal-based chemotherapy against tropical diseases: 1. Enhancement of the efficacy of clotrimazole against Trypanosoma cruzi by complexation to ruthenium in $\mathrm{RuCl}_{2}$ (clotrimazole) $)_{2}$. J Med Chem 36:2041-2043
34. Sánchez-Delgado RA, Navarro M, Pérez H, Urbina JA (1996) Toward a novel metal-based chemotherapy against tropical diseases: 2. Synthesis and antimalarial activity in vitro and in vivo of new ruthenium- and rhodium-chloroquine complexes. J Med Chem 39:1095-1099

35. Navarro M, Pérez H, Sánchez-Delgado RA (1997) Toward a novel metal-based chemotherapy against tropical diseases: 3. Synthesis and antimalarial activity in vitro and in vivo of the new goldchloroquine complex $\left[\mathrm{Au}\left(\mathrm{PPh}_{3}\right)(\mathrm{CQ})\right] \mathrm{PF}_{6}$. J Med Chem 40:19371939. doi:10.1021/jm9607358

36. Sánchez-Delgado RA, Navarro M, Lazardi K, Atencio R, Capparelli M, Vargas F, Urbina JA, Bouillez A, Noels AF, Masi D (1998) Toward a novel metal-based chemotherapy against tropical diseases: 4. Synthesis and characterization of new metalclotrimazole complexes and evaluation of their activity against Trypanosoma cruzi. Inorg Chim Acta 275-276:528-540

37. Navarro M, Lehmann T, Cisneros-Fajardo EJ, Fuentes A, SánchezDelgado RA, Silva P, Urbina JA (2000) Toward a novel metalbased chemotherapy against tropical diseases: Part 5. Synthesis and characterization of new $\mathrm{Ru}(\mathrm{II})$ and $\mathrm{Ru}(\mathrm{III})$ clotrimazole and ketoconazole complexes and evaluation of their activity against Trypanosoma cruzi. Polyhedron 19:2319-2325. doi:10.1016/ S0277-5387(00)00495-2

38. Navarro M, Cisneros-Fajardo EJ, Lehmann T, Sánchez-Delgado RA, Atencio R, Silva P, Lira R, Urbina JA (2001) Toward a novel metal-based chemotherapy against tropical diseases: 6 . Synthesis and characterization of bew copper(II) and gold(I) clotrimazole and ketoconazole complexes and evaluation of their activity against Trypanosoma cruzi. Inorg Chem 40:6879-6884. doi:10.1021/ic0103087

39. Navarro M, Vasquez F, Sanchez-Delgado RA, Perez H, Sinou V, Schrevel J (2004) Toward a novel metal-based chemotherapy against tropical diseases: 7. Synthesis and in vitro antimalarial activity of new gold-chloroquine complexes. J Med Chem 47:5204-5209. doi:10.1021/jm049792o

40. Navarro M (2009) Gold complexes as potential anti-parasitic agents. Coord Chem Rev 253:1619-1626. doi:10.1016/ j.ccr.2008.12.003

41. Bryan M, Guyach S, Norris K (2013) Biolistic DNA vaccination against trypanosoma infection. In: Sudowe S, Reske-Kunz AB (eds) Biolistic DNA delivery, vol. 940. Methods in molecular biology. Humana Press, pp 305-315. doi:10.1007/978-1-62703-110-3 23

42. Santos MAM, de Andrade PP, de Andrade CR, Padovan PA, de Souza W (1991) Effect of trypsin and 2-mercaptoethanol on the exposure of sugar residues on the surface of Leishmania donovani chagasi. Parasitol Res 77:553-557

43. Borges VM, Vannier-Santos MA, de Souza W (1998) Subverted transferrin trafficking in Leishmania-infected macrophages. Parasitol Res 84:811-822. doi:10.1007/s004360050493

44. Sengupta S, Tripathi J, Tandon R, Raje M, Roy RP, Basu SK, Mukhopadhyay A (1999) Hemoglobin endocytosis in Leishmania is mediated through a $46-\mathrm{kDa}$ protein located in the flagellar pocket. J Biol Chem 274:2758-2765. doi:10.1074/jbc.274.5.2758

45. Zijlstra EE, Nur Y, Desjeux P, Khalil EAG, El-Hassan AM, Groen J (2001) Diagnosing visceral leishmaniasis with the recombinant K39 strip test: experience from the Sudan. Trop Med Int Health 6:108-113. doi:10.1046/j.1365-3156.2001.00680.x

46. Carreira JCA, da Silva AVM, de Pita PD, Brazil RP (2012) Natural infection of Didelphis aurita (Mammalia: Marsupialia) with Leishmania infantum in Brazil. Parasites Vectors 5:111115. doi:10.1186/1756-3305-5-111

47. Ramos-Jesus J, Carvalho KA, Fonseca RAS, Oliveira GGS, Barrouin Melo SM, Alcantara-Neves NM, Dutra RF (2011) A piezoelectric immunosensor for Leishmania chagasi antibodies in canine serum. Anal Bioanal Chem 401:917-925. doi:10.1007/ s00216-011-5136-7 
48. Moreno M, Rincon E, Pineiro D, Fernandez G, Domingo A, Jimenez-Ruiz A, Salinas M, Gonzalez VM (2003) Selection of aptamers against KMP-11 using colloidal gold during the SELEX process. Biochem Biophys Res Commun 308:214-218. doi:10.1016/s0006-291x(03)01352-4

49. Moreno M, Gonzalez VM, Rincon E, Domingo A, Dominguez E (2011) Aptasensor based on the selective electrodeposition of protein-linked gold nanoparticles on screen-printed electrodes. Analyst 136:1810-1815. doi:10.1039/c1an15070g

50. Ilari A, Baiocco P, Messori L, Fiorillo A, Boffi A, Gramiccia M, Di Muccio T, Colotti G (2012) A gold-containing drug against parasitic polyamine metabolism: the X-ray structure of trypanothione reductase from Leishmania infantum in complex with auranofin reveals a dual mechanism of enzyme inhibition. Amino Acids 42:803-811. doi:10.1007/s00726-011-0997-9

51. Navarro M, Hernandez C, Colmenares I, Hernandez P, Fernandez M, Sierraalta A, Marchan E (2007) Synthesis and characterization of $\left[\mathrm{Au}(\mathrm{dppz})_{2}\right] \mathrm{Cl}_{3}$. DNA interaction studies and biological activity against Leishmania (L) mexicana. J Inorg Biochem 101:111-116. doi:10.1016/j.jinorgbio.2006.08.015

52. Barboza-Filho CG, Cabrera FC, Dos Santos RJ, De Saja Saez JA, Job AE (2012) The influence of natural rubber/Au nanoparticle membranes on the physiology of Leishmania brasiliensis. Exp Parasitol 130:152-158. doi:10.1016/j.exppara.2011.10.015

53. Sazgarnia A, Taheri AR, Soudmand S, Parizi AJ, Rajabi O, Darbandi MS (2013) Antiparasitic effects of gold nanoparticles with microwave radiation on promastigots and amastigotes of Leishmania major. Int J Hyperth 29:79-86. doi:10.3109/ 02656736.2012 .758875

54. Bhowmick IP, Kumar N, Sharma S, Coppens I, Jarori GK (2009) Plasmodium falciparum enolase: stage-specific expression and sub-cellular localization. Malaria Journal 8. doi:10.1186/14752875-8-179

55. Chugh M, Gulati BR, Gakhar SK (2010) Monoclonal antibodies AC-43 and AC-29 disrupt Plasmodium vivax development in the Indian malaria vector Anopheles culicifacies (Diptera: culicidae). J Biosci 35:87-94. doi:10.1007/s12038-010-0011-9

56. Lopes da Silva M, Thieleke-Matos C, Cabrita-Santos L, Ramalho JS, Wavre-Shapton ST, Futter CE, Barral DC, Seabra MC (2012) The host endocytic pathway is essential for Plasmodium berghei late liver stage development. Traffic 13:1351-1363. doi:10.1111/ j.1600-0854.2012.01398.x

57. Stevens DY, Petri CR, Osborn JL, Spicar-Mihalic P, McKenzie KG, Yager P (2008) Enabling a microfluidic immunoassay for the developing world by integration of on-card dry reagent storage. Lab Chip 8:2038-2045. doi:10.1039/b811158h

58. Sharma MK, Agarwal GS, Rao VK, Upadhyay S, Merwyn S, Gopalan N, Rai GP, Vijayaraghavan R, Prakash S (2010) Amperometric immunosensor based on gold nanoparticles/alumina solgel modified screen-printed electrodes for antibodies to Plasmodium falciparum histidine rich protein-2. Analyst 135:608-614. doi:10.1039/b918880k

59. Fu E, Liang T, Spicar-Mihalic P, Houghtaling J, Ramachandran S, Yager P (2012) Two-dimensional paper network format that enables simple multistep assays for use in low-resource settings in the context of malaria antigen detection. Anal Chem 84:45744579. doi:10.1021/ac300689s

60. Nash MA, Waitumbi JN, Hoffman AS, Yager P, Stayton PS (2012) Multiplexed enrichment and detection of malarial biomarkers using a stimuli-responsive iron oxide and gold nanoparticle reagent system. ACS Nano 6:6776-6785. doi:10.1021/ nn3015008

61. Potipitak T, Ngrenngarmlert W, Promptmas C, Chomean S, Ittarat W (2011) Diagnosis and genotyping of Plasmodium falciparum by a DNA biosensor based on quartz crystal microbalance (QCM). Clin Chem Lab Med 49:1367-1373. doi:10.1515/cclm.2011.178
62. Guirgis BSS, Sa e Cunha C, Gomes I, Cavadas M, Silva I, Doria G, Blatch GL, Baptista PV, Pereira E, Azzazy HME, Mota MM, Prudencio M, Franco R (2012) Gold nanoparticle-based fluorescence immunoassay for malaria antigen detection. Anal Bioanal Chem 402:1019-1027. doi:10.1007/s00216-011-5489-y

63. Piper RC, Buchanan I, Choi YH, Makler MT (2011) Opportunities for improving $\mathrm{pLDH}$-based malaria diagnostic tests. Malaria Journal 10. doi:10.1186/1475-2875-10-213

64. Peng Y, Wu J, Wang J, Li W, Yu S (2012) Study and evaluation of Wondfo rapid diagnostic kit based on nanogold immunochromatography assay for diagnosis of Plasmodium falciparum. Parasitol Res 110:1421-1425. doi:10.1007/ s00436-011-2643-6

65. Navarro M, Castro W, Martinez A, Sanchez-Delgado RA (2011) The mechanism of antimalarial action of $\left[\mathrm{Au}(\mathrm{CQ})\left(\mathrm{PPh}_{3}\right)\right] \mathrm{PF}_{6}$ : structural effects and increased drug lipophilicity enhance heme aggregation inhibition at lipid/water interfaces. J Inorg Biochem 105:276-282. doi:10.1016/j.jinorgbio.2010.11.005

66. Blackie MAL, Beagley P, Chibale K, Clarkson C, Moss JR, Smith PJ (2003) Synthesis and antimalarial activity in vitro of new heterobimetallic complexes: $\mathrm{Rh}$ and $\mathrm{Au}$ derivatives of chloroquine and a series of ferrocenyl-4-amino-7-chloroquinolines. J Organomet Chem 688:144-152. doi:10.1016/j.jorganchem.2003.07.026

67. Fricker SP, Mosi RM, Cameron BR, Baird I, Zhu Y, Anastassov V, Cox J, Doyle PS, Hansell E, Lau G, Langille J, Olsen M, Qin L, Skerlj R, Wong RSY, Santucci Z, McKerrow JH (2008) Metal compounds for the treatment of parasitic diseases. J Inorg Biochem 102:1839-1845. doi:10.1016/j.jinorgbio.2008.05.010

68. Sannella AR, Casini A, Gabbiani C, Messori L, Bilia AR, Vincieri FF, Majori G, Severini C (2008) New uses for old drugs. Auranofin, a clinically established antiarthritic metallodrug, exhibits potent antimalarial effects in vitro: mechanistic and pharmacological implications. FEBS Lett 582:844-847. doi:10.1016/ j.febslet.2008.02.028

69. Bjelosevic H, Guzei IA, Spencer LC, Persson T, Kriel FH, Hewer R, Nell MJ, Gut J, Van Rensburg CEJ, Rosenthal PJ, Coates J, Darkwa J, Elmroth SKC (2012) Platinum(II) and gold(I) complexes based on 1,1'-bis(diphenylphosphino)metallocene derivatives: synthesis, characterization and biological activity of the gold complexes. J Organomet Chem 720:52-59. doi:10.1016/ j.jorganchem.2012.08.034

70. Hemmert C, Fabié A, Fabre A, Benoit-Vical F, Gornitzka H (2013) Synthesis, structures, and antimalarial activities of some silver(I), gold(I) and gold(III) complexes involving $N$-heterocyclic carbene ligands. Eur J Med Chem 60:64-75. doi:10.1016/ j.ejmech.2012.11.038

71. Soni N, Prakash S (2012) Entomopathogenic fungus generated nanoparticles for enhancement of efficacy in Culex quinquefasciatus and Anopheles stephensi. Asian Pac J Trop Dis 2:S356-S361. doi:10.1016/S2222-1808(12)60181-9

72. Thet W, Thein T (1987) Rapid and sensitive detection of dengue viral antigen using immunogold in light microscopy and solid phase gold immunoassay (SPGIA). Microbiol Immunol 31:183-188

73. Chen WJ, Chen SL, Fang AH, Wang MT (1993) Detection of dengue virus antigens in cultured cells by using protein A-goldsilver staining (pAgs) method. Microbiol Immunol 37:359-363

74. Vancini R, Kramer LD, Ribeiro M, Hernandez R, Brown D (2013) Flavivirus infection from mosquitoes in vitro reveals cell entry at the plasma membrane. Virology 435:406-414. doi:10.1016/ j.virol.2012.10.013

75. Kumbhat S, Sharma K, Gehlot R, Solanki A, Joshi V (2010) Surface plasmon resonance based immunosensor for serological diagnosis of dengue virus infection. J Pharm Biomed Anal 52:255-259. doi:10.1016/j.jpba.2010.01.001

76. Hsu IH, Chen W-H, Wu T-K, Sun Y-C (2011) Gold nanoparticlebased inductively coupled plasma mass spectrometry amplification 
and magnetic separation for the sensitive detection of a virusspecific RNA sequence. J Chromatogr A 1218:1795-1801. doi:10.1016/j.chroma.2011.02.005

77. Nascimento HPO, Oliveira MDL, de Melo CP, Silva GJL, Cordeiro MT, Andrade CAS (2011) An impedimetric biosensor for detection of dengue serotype at picomolar concentration based on gold nanoparticles-polyaniline hybrid composites. Colloids Surf B: Biointerfaces 86:414-419. doi:10.1016/ j.colsurfb.2011.04.028

78. Vazquez S, Lemos G, Pupo M, Ganzon O, Palenzuela D, Indart A, Guzman MG (2003) Diagnosis of dengue virus infection by the visual and simple AuBioDOT immunoglobulin M Capture system. Clin Diagn Lab Immunol 10:1074-1077. doi:10.1128/ cdli.10.6.1074-1077.2003

79. Li YT, Liu HS, Lin HP, Chen SH (2005) Gold nanoparticles for microfluidics-based biosensing of PCR products by hybridizationinduced fluorescence quenching. Electrophoresis 26:4743-4750. doi:10.1002/elps.200500481

80. Oliveira MDL, Correia MTS, Diniz FB (2009) Concanavalin A and polyvinyl butyral use as a potential dengue electrochemical biosensor. Biosens Bioelectron 25:728-732. doi:10.1016/ j.bios.2009.08.009

81. Oliveira MDL, Correia MTS, Diniz FB (2009) A novel approach to classify serum glycoproteins from patients infected by dengue using electrochemical impedance spectroscopy analysis. Synth Met 159:2162-2164. doi:10.1016/j.synthmet.2009.09.022

82. Cavalcanti IT, Guedes MIF, Sotomayor MDPT, Yamanaka H, Dutra RF (2012) A label-free immunosensor based on recordable compact disk chip for early diagnostic of the dengue virus infection. Biochem Eng J 67:225-230. doi:10.1016/j.bej.2012.06.016

83. Muller DA, Corrie SR, Coffey J, Young PR, Kendall MA (2012) Surface modified microprojection arrays for the selective extraction of the dengue virus NS1 protein as a marker for disease. Anal Chem 84:3262-3268. doi:10.1021/ac2034387

84. Andrade CAS, Oliveira MDL, de Melo CP, Coelho LCBB, Correia MTS, Nogueira ML, Singh PR, Zeng X (2011) Diagnosis of dengue infection using a modified gold electrode with hybrid organic-inorganic nanocomposite and Bauhinia monandra lectin. J Colloid Interface Sci 362:517-523. doi:10.1016/j.jcis.2011.07.013

85. Chen S-H, Chuang Y-C, Lu Y-C, Lin H-C, Yang Y-L, Lin C-S (2009) A method of layer-by-layer gold nanoparticle hybridization in a quartz crystal microbalance DNA sensing system used to detect dengue virus. Nanotechnology 20:215501. doi:10.1088/ 0957-4484/20/21/215501

86. Oliveira MDL, Nogueira ML, Correia MTS, Coelho LCBB, Andrade CAS (2011) Detection of dengue virus serotypes on the surface of gold electrode based on Cratylia mollis lectin affinity. Sensors Actuators B Chem 155:789-795. doi:10.1016/ j.snb.2011.01.049

87. Vaughan S, Gull K (2003) The trypanosome Flagellum. J Cell Sci 116:757-759. doi:10.1242/jcs.00287

88. Chaves CR, Fontes A, Farias PMA, Santos BS, de Menezes FD, Ferreira RC, Cesar CL, Galembeck A, Figueiredo RCBQ (2008) Application of core-shell PEGylated $\mathrm{CdS} / \mathrm{Cd}(\mathrm{OH})_{2}$ quantum dots as biolabels of Trypanosoma cruzi parasites. Appl Surf Sci 255:728-730. doi:10.1016/j.apsusc.2008.07.035 